\title{
HERNIA INTERNA SECUNDARIA A DIVERTÍCULO DE MECKEL COMPLICADO*
}

\author{
Drs. Felipe Imigo G. ${ }^{1}$, Erick Castillo F. ${ }^{1}$, Eduardo Rosa C. ${ }^{2}$ \\ 1 Cirujano general, Hospital Puerto Montt. \\ 2 Instructor Cirugía, Campus Puerto Montt, Universidad San Sebastián. \\ 3 Médico Radiólogo, Clínica Los Andes, Puerto Montt. \\ Chile.
}

\section{Internal hernia secondary to complicated Meckel's diverticulum}

Mujer de 22 años con antecedentes de apendicectomía clásica. Consultó en urgencia por cuadro clínico de 3 días de evolución de obstrucción intestinal. Se solicitó tomografía computada de abdomen y pelvis con contraste, la cual evidenció signos de obstrucción intestinal de intestino delgado con cambio brusco de calibre del íleon medio a nivel de la fosa iliaca derecha (Figura 1).

Se realizó laparotomía exploradora apreciando a nivel de íleon medio a $60 \mathrm{~cm}$ de la válvula ileocecal un divertículo de Meckel (DM), inflamado en su tercio medio y distal, íntimamente adherido al mesenterio ileal, el cual condiciona hernia interna a través de la que se introduce segmento de íleon proximal, el que está atascado (Figuras 2 y 3 ). Se desobstruye intestino apreciando en la base del divertículo una estenosis significativa (Figura 4), motivo por el cual se decide resección intestinal y anastomosis laterolateral. La evolución postoperatoria no presentó incidentes. La biopsia de la pieza quirúrgica concluyó DM con signos de inflamación difusa, no apreciando tejido ectópico

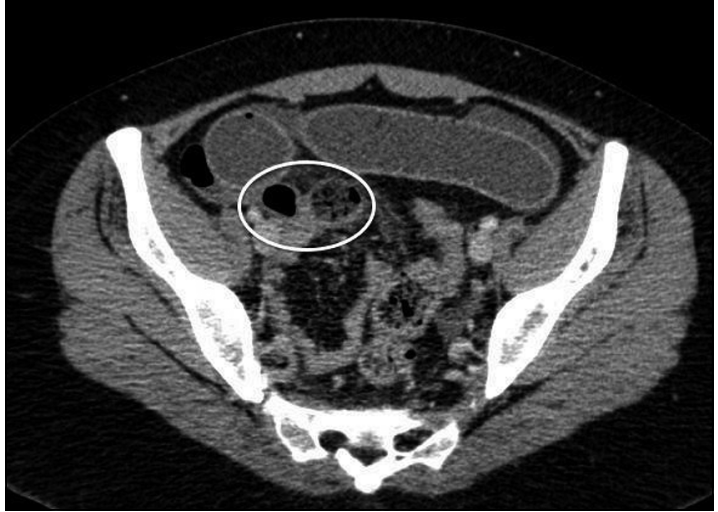

Figura 1. TC que muestra la obstrucción intestinal.

La complicación de los DM en el adulto es infrecuente siendo la obstrucción intestinal la más común, determinada por un mecanismo de invaginación, bezoares y/o hernia de Littre siendo la hernia interna extremadamente raro $^{1-4}$.

*Recibido el 22 de enero de 2015 y aceptado para publicación el 21 de febrero de 2015.

Los autores no refieren conflictos de interés.

Correspondencia: Dr. Felipe Imigo G.

felipeimigo@gmail.com 


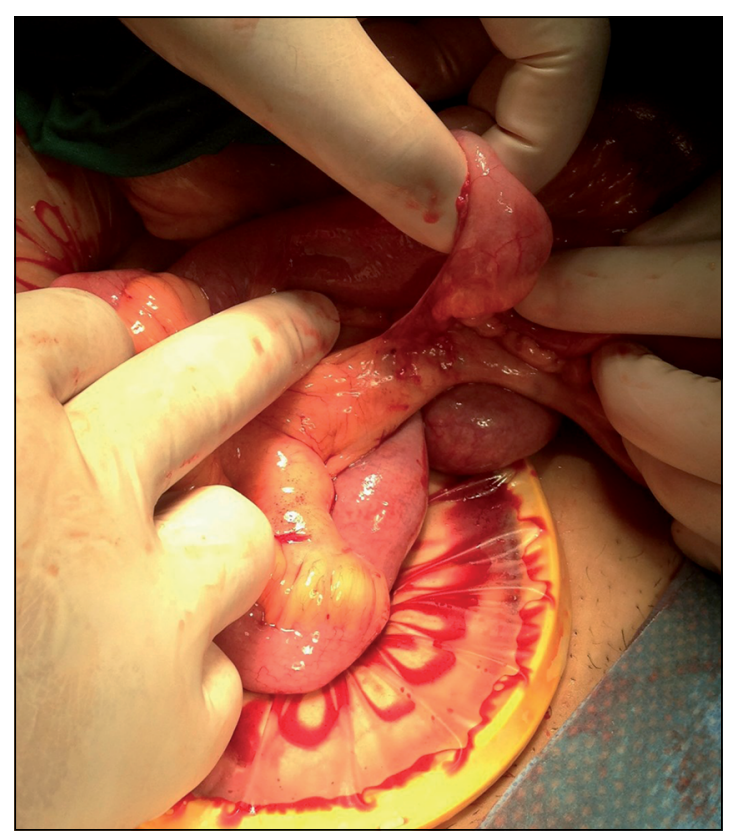

Figura 2. Hernia interna.

\section{Referencias}

1. Dumper J, Mackenzie S, Mitchell P, Sutherland F, Lynn M. Complications of Meckel's diverticula in adults. Can J Surg. 2006;49:353-8.

2. Park J, Wolff B, Tollefson M, Walsh E, Larson D. The Mayo Clinic Experience with 1476 Patients (19502002). Ann Surg. 2005;241:529-33.

3. Groebli Y, Bertin D, Morel P. Meckel's diverticulum in adults: retrospective analysis of 119 cases and historical review. Eur J Surg. 2001;167:518-24.

4. Estrella M, Bernal J, Fuenzalida L. Hernia interna de divertículo de Meckel como causa de obstrucción intestinal en un senescente. Rev Chil Cir. 2009;61:187-90.

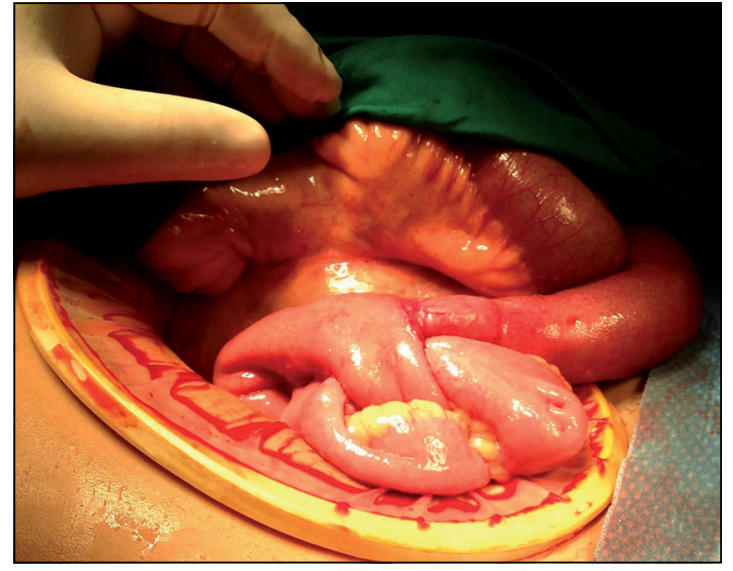

Figura 3. Hernia interna.

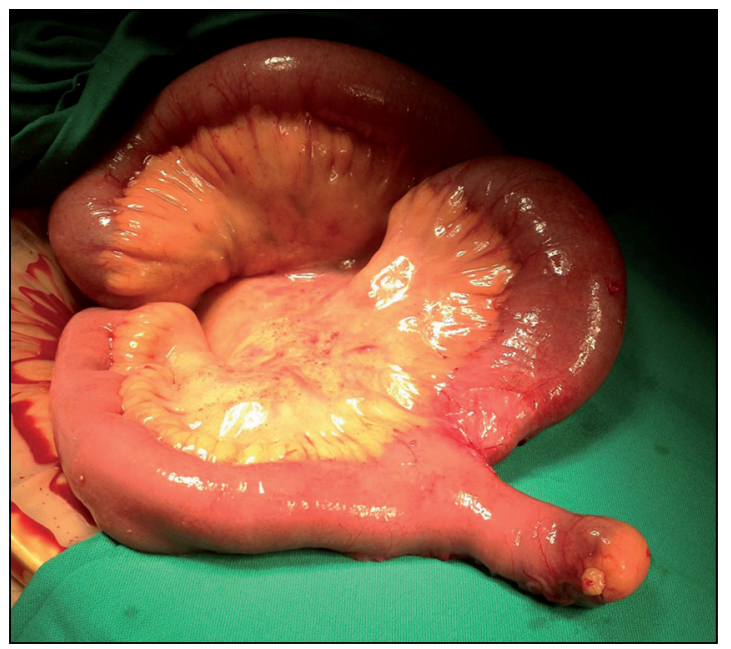

Figura 4. Divertículo con estenosis en la base. 